\title{
Technology-Enhanced Learning Environments and Adaptive Learning Systems - Development of Functionality Taxonomies
}

\author{
Alina Bockshecker \\ University of Hagen \\ alina.bockshecker@fernuni- \\ hagen.de
}

\author{
Katharina Ebner \\ University of Hagen \\ katharina.ebner@fernuni- \\ hagen.de
}

\author{
Stefan Smolnik \\ University of Hagen \\ stefan.smolnik@fernuni- \\ hagen.de
}

\begin{abstract}
Especially against the background of the current coronavirus crisis, technology-enhanced learning environments (TELEs) increasingly characterize teaching at universities. For the successful use and integration of TELEs, it is important to understand the functionalities of the technologies used. Based on the state of the art and following [1], we develop two taxonomies. The first taxonomy depicts eleven functionalities with different dimensions relevant for successfully designing TELEs. Sound knowledge of the functionalities supports research on adaptive learning within TELEs and the implementation of studentcentered learning opportunities, which is structured in a second functionality taxonomy for adaptive learning systems (ALSs). We contribute to current research on TELEs and ALSs by providing a structured overview of functionalities and suggestions for further research with our research opportunities.
\end{abstract}

\section{Introduction}

The coronavirus crisis currently accelerates the digital transformation of many organizations [2-4] "inflicting an uncertainty shock" [5, p.128]. "This is especially true of the university sector where many universities have digitalized all their teaching activities to cope with the situation" [2, p.2]. Technology-enhanced learning environments (TELEs) [6] present means of addressing this transformation accelerated by emergency remote teaching [3]. The crisis challenges universities to introduce and use TELEs in all study courses to continue teaching, even in times of restricted or forbidden physical attendance as in classroom or laboratory lectures.

Since the means whereby these environments integrate technology into learning processes is said to improve learning outcomes [7], TELEs have been discussed before the crisis. TELEs enable adaptive learning [8], thus allowing not only students to learn at their own pace [9] but also to adjust "instructional actions" according to the students' characteristics [10, p.336]. Scientific research emphasizes different relevant aspects of TELEs. First, the importance of students' digital literacy and the lecturers' competence is discussed [11], resulting in recommendations to address and improve them. Second, the relevance of students' characteristics and acceptance is highlighted [4], and effects as well as requirements for the design of TELEs are presented. Third, detailed information on the technology used is provided along with critical success factors for the implementation in TELEs [12]. While these three aspects emphasize the various existing research findings that focus on specific aspects of TELEs, a structured overview of TELE functionalities to enable meaningful decision making for implementing functionalities is often left to future research $[4,7]$.

We address this desideratum by developing taxonomies that provide a systematic classification of TELE functionalities. Generally, taxonomies are "systems of groupings that are derived conceptually or empirically" [1, p.338], consisting of a number of dimensions. Each dimension is further explained by "mutually exclusive and collectively exhaustive characteristics" [1, p.340]. Such taxonomies are a basis for further structured analysis and design of individualized environments for different learning settings and goals. The relevance of personalization is

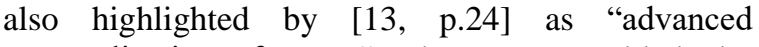
personalization features" that are enabled by functionalities, such as "modularity, extendibility, adaptability" [13, p.24]. An adaptive learning system (ALS) automatically adjusts as different students complete the course and their response records detect errors in instructional strategies [10]. ALSs provide learning content that can be tailored to each student's specific needs and requirements at an appropriate time [14]. In ALSs, it is possible to modify the learning content, the presentation of the content, and many other distinct aspects depending on the learners' 
characteristics [15]. These learner characteristics are of interest in ALS design, as are the similarities a learner shares with others, the learners' interactional behavior, and the learning progress [14]. For the design of such environments, it is important to identify the TELEs' available functionalities.

In sum, we address the following research questions: (1) How can functionalities in TELEs be divided into meaningful dimensions? (2) Which of these functionality dimensions in TELEs enable adaptive learning?

We further analyze the functionalities of ALSs integrated into TELEs by investigating the corresponding taxonomies' dimensions. Our contribution is twofold. First, a systematic identification and derivation of research opportunities on TELEs and ALSs in higher education is enabled and is presented here. Second, practitioners, for example, in the current coronavirus crisis, can use our contribution to design courses and environments that meet the challenges of current times. The taxonomy may also be useful for university units implementing and innovating teaching and learning environments.

\section{Adaptive learning systems in technology-enhanced learning environments}

\subsection{Technology-enhanced learning environments}

The term "learning environment" can be defined as "a social system, focusing on the continuous development and validation of human knowledge and skills in a particular domain" [16, p.1861]. In line with [7], whenever we refer from hereon to TELEs, we understand a learning environment that requires but does not rely solely on the integration and use of technology in courses (e.g. due to didactical purposes). Furthermore, it can also be highlighted that "for any type of profound learning to take place, more interactive teaching methods must be utilized" by "creatively" [17, p.169f.] incorporating technologies into the learning environment. The authors also highlight the importance of sharing knowledge and experience with other students in the learning environment [17]. Complementing these positions, [18] suggest that technology-enhanced personalized learning should also enable the learner to have a certain degree of autonomy in deciding what, when, how, and where to learn, thus reflecting the adaptive learning concept.

To design TELEs that enable adaptive learning, the functionalities of the different technological approaches must be known because these functionalities not only guide and encourage thinking but also facilitate the acquisition of higher order skills [17]. With a systematic literature review, [19] analyze the optimization potential different learning environments have by combining learning analytics and learning design to direct future learning "towards personalizing learners' experiences and adapting it to their strengths, interest, and aspirations" [19, p.531]. By analyzing learning activities at the Open University in UK, it is also shown that a variety of learning design activities exist for distance higher education [20]. Since many research results focus and are based on specific aspects of TELEs, they do not provide a holistic overview. With our paper, we aim at analyzing and classifying such functionalities in a structured manner.

In addition, taxonomies provide a special contribution to the field of TELEs, for example, by structuring ethical issues [21] or teacher competence to design learning environments [22]. [21] proposes a taxonomy of ethical issues for mobile learning based on meta-ethical moral theory. Furthermore, [21] highlights the importance of supporting teachers in the process of designing TELEs for their 21st century teaching and proposes a teacher design knowledge competency taxonomy with four practices: (a) Data practice, (b) design practice, (c) knowledge creation practice, and (d) professional teaching practice, are emphasized [22]. The taxonomy is supposed to help teachers identify their design competencies and encourages them to identify their own designing strengths [22]. We provide a structured overview of functionalities in two taxonomies that focus on different aspects of TELEs and ALSs to support research and practitioners to design their digital learning environments.

\subsection{Adaptive learning system}

The idea of an ALS is not a new one. Already in 1974, Atkinson referred to adaptive instructional systems, that considering the students' performance history, "vary the instructional actions taken by the program" [10, p.336]. Furthermore, the adaptive instructional system can "modify itself automatically as more students complete the course and their response records identify defects in instructional strategies" [10, p.336]. Through increasingly integrating technologies into learning environments, implementing an ALS in higher education allows not only for the provision of the flexibility and autonomy demanded by students but also for the individualization of the ALS according to users' needs [23]. 
Mentoring a large number of students is an important requirement of higher education institutions. A mean to address this, is to integrate ALSs into existing learning environments to provide individual learning support for the students. Prior research on adaptive learning technologies has highlighted the opportunity to minimize the "negative impacts of individual differences including knowledge, social economic class, personal needs and disabilities" [24, p.1891] using adaptive learning, for example, in the form of intelligent tutoring systems. [25] supports this argument explicitly for computerbased adaptive learning. Scientific researchers also analyzed the implementation of adaptive learning in different settings, for example, at a university in mathematics [26] and in high school classes [27].

While previous research has tried to investigate first attempts at integrating adaptive learning into TELEs and learning designs to improve learning experience through individualization, our research is interested in investigating how functionalities in TELEs can be divided into meaningful dimensions and how they support adaptive learning in TELEs.

\section{Research method and process}

To address the described research problem, we first develop a taxonomy of TELEs' functionalities (Section 4.) and, second, a functionality taxonomy of ALSs (Section 6.1.). We developed the taxonomies according to the development method by Nickerson et al. [1]. The method is widely accepted in information systems research and is a structural rather than an ad hoc development approach [28], consisting of seven steps, which are illustrated in Figure 1.

The definition of the first two steps toward the first taxonomy (determine meta-characteristic and ending conditions, see Figure 1) has a great influence on the resulting taxonomy, as other metacharacteristics and ending conditions lead to completely different results. Step 1 determines the meta-characteristics and forms the basis for successfully developing the taxonomy [1]. We chose technological functionalities of TELEs as our metacharacteristic. The potential users of our taxonomy are researchers who analyze TELEs and ALSs, and design environments in this field, as well as practitioners who use functionalities in TELEs and want to design their TELEs to support their students in adaptive learning. The taxonomy supports the identification of technologies and their functionalities to define which dimensions are best suited to support adaptive learning within their TELEs. The purpose of our taxonomy is to distinguish various dimensions in learning technologies that enable adaptive learning, and to propose a scientifically derived basis for the structured implementation of adaptive learning in TELEs.

In step two, we specified the ending condition of the iterative taxonomy development process. Various options of objective and subjective ending conditions exist. We chose "at least one object is classified under every characteristics of every dimension adding no new dimensions or characteristics in the last iteration" [1, p.344]. Furthermore, we also chose to neither merge nor split any dimensions or characteristics in the last iteration, as these conditions avoid inefficient iterations, with little to no improvements or additions to the taxonomy.

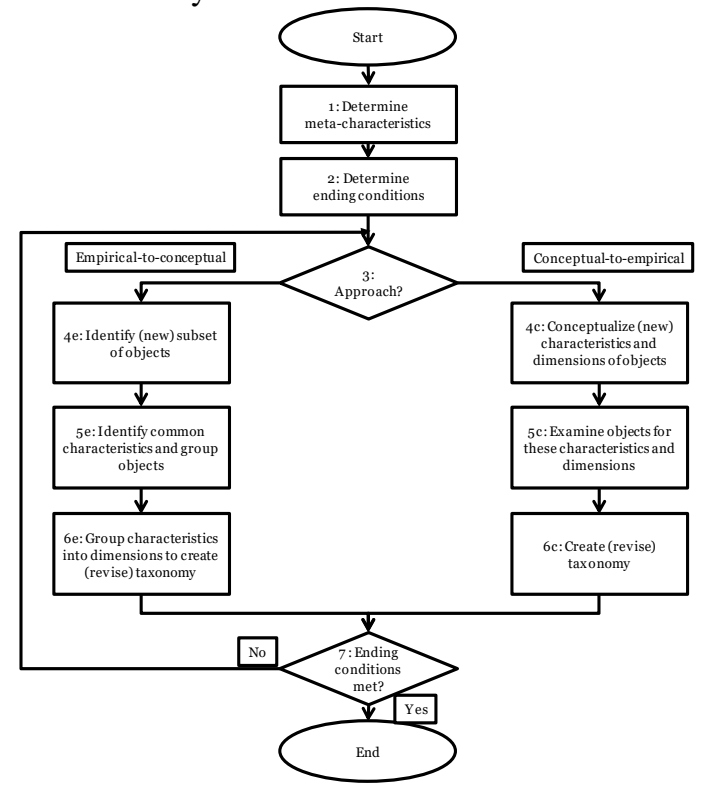

Figure 1. Taxonomy development method [1]

We decided first to use the conceptual-toempirical approach for step three. We, therefore, conducted a literature search. For identifying functionalities in TELEs, our search focused on "functionalities of TELEs" and related search terms, such as "technology enhanced learning." We browsed the EBSCOhost (Business Source Ultimate) database and the Learning \& Technology Library (LearnTechLib) for peer reviewed full research papers. We chose 2012 as starting date because digitalization has led to rapid changes in functionalities of learning technologies in the last years. The results and their distribution of publication dates highlight the increasing importance of functionalities in scientific discussions. This very broad starting point led to 62 results in the EBSCOhost database and 382 results in the LearnTechLib. Analyzing the recent research builds the basis for the conceptual-to-empirical part of developing the taxonomy [1]. 


\section{Developing the TELEs' functionality taxonomy}

Within the seven iterations of conceptual-toempirical [1], we derived 11 functionalities from the analyzed scientific research (Table 1) and reached the previously defined ending condition. We searched all previously identified papers for functionalities and collected them first before clustering them. The analysis showed that many papers only mention functionalities but do not explain their exact dimensions [e.g. 29]. The next iteration was, therefore, used particularly to search for dimensions of the functionalities identified in the previous iteration; alternatively, we focused on identifying a term that fits previously discovered dimensions. With the first iteration, we identified seven functionalities: delivery, responsiveness, access, symmetry, authority, personalization, and adaptability [30]. Consequently, in a second and third step, the functionalities were the focus of the iterations. While we also identified four of these functionalities in other research and retained them in the taxonomy, we merged two of the mentioned functionalities with other functionalities and their dimensions. We did not specify one of those functionalities in the taxonomy, since we could not identify the concept and the underlying dimensions appropriately in other research, and it was not defined in other research we analyzed. Iterations four to six brought up the other functionalities and their dimensions. In the seventh iteration, we could not add further functionalities or dimensions to the taxonomy, which met the previously defined ending condition.
The iterations and synthesis led to the taxonomy given in Table 1 below, consisting of eleven functionalities sorted alphabetically and all derived through the structured process of taxonomy development.

The functionality access ensures accessibility for all learners [31] to the learning content within the TELE. The dimension immediacy allows for instant access through a web browser independent of the laptop or device being used. Immediacy is related to the second dimension compatibility. TELEs should be compatible with different operating systems of the laptops or devices students use [32] and are, therefore, accessible to all learners.

The functionality adaptability consists of a variety of dimensions with sub-dimensions that result in a more precise taxonomy especially for TELEs that enable adaptive learning systems (see below). For this more general taxonomy, we decided to follow [33] with the differentiations in five consecutive levels. The first level, basic automation, includes systems that provide basic infrastructure and features, for example, content management and calendar. Managed automation is the second level, and is based on the first level but includes additional features, such as data collection "to improve efficiency and productivity" [33, p.583f.]. The third level, predictive, provides opportunities for monitoring and comparing students' learning progress and allows the identification of potential difficulties. The fourth level, adaptive, is consistent with the explanations above in Section 2.2. The fifth level, automation, goes beyond adaptivity and refers to "fully integrated systems" enabling enhanced "efficiencies, self-healing computer failures, self-protection for security capabilities" [33, p.583f.].

Table 1. Taxonomy of functionalities in technology-enhanced learning environments

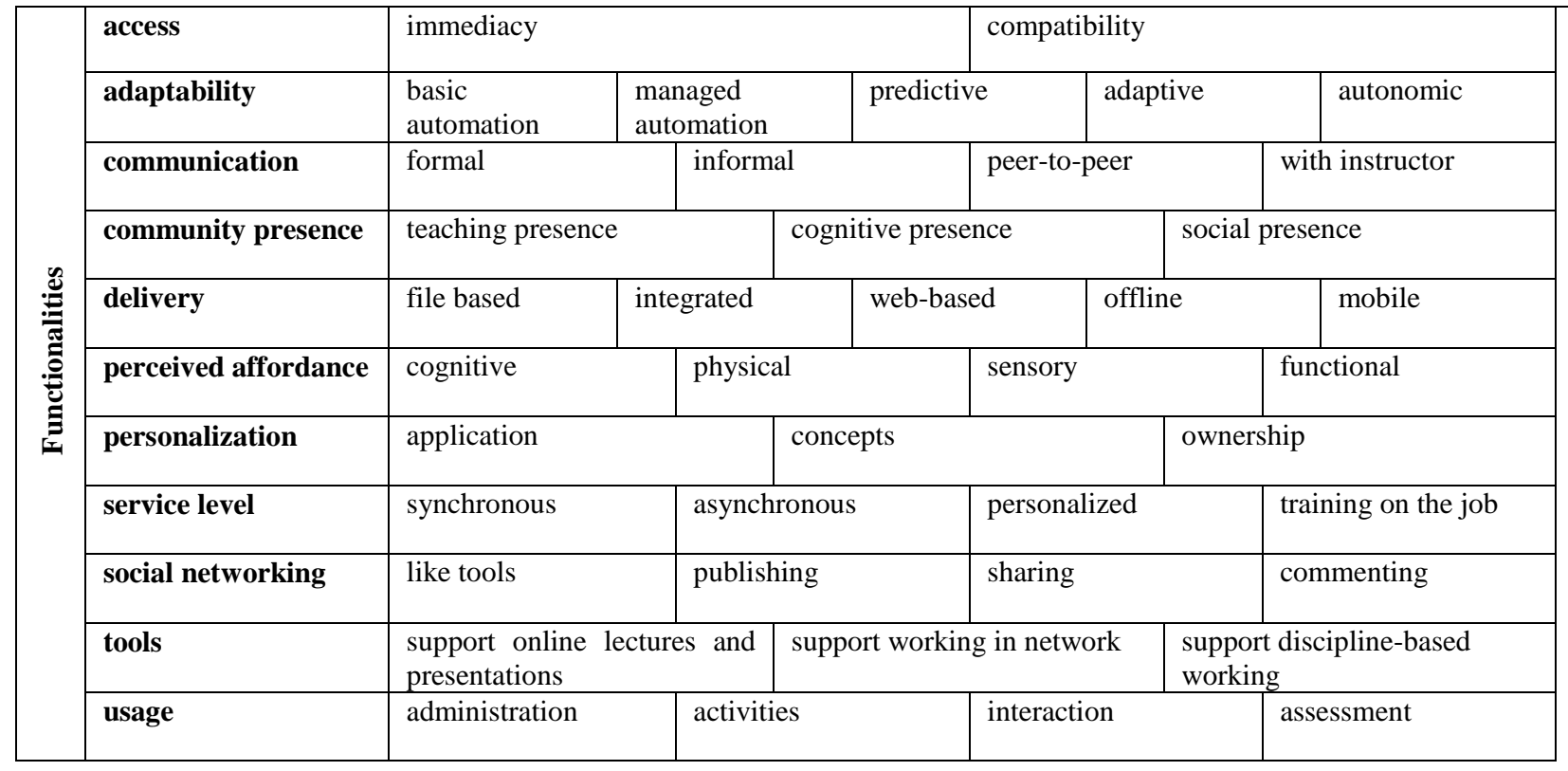


Communication in TELEs can either be formal or informal (especially relevant in combination with the social networking dimensions). The communication enabled in TELEs might be restricted to communication with the course instructors or with other learners about the learning content [20], or offer communication with both these user groups. Communication is an important functionality of TELEs, as teaching and learning are highly interactive. The chosen characteristics must meet the individual preferences of users (e.g. lecturers), but of course must also be incorporated into the efficient and effective design of TELEs. For practitioners and researchers, the design of this functionality is therefore of great importance.

The learner's different community presences date back to the constructivist learning theory that highlights learning as a process [29]. Students working together in TELEs as a community of learners can share in teaching presence, cognitive presence, and social presence [34]. "Cognitive presence is a vital element in critical thinking, a process and outcome that is frequently presented as the ostensible goal of all higher education" [35, p.89]. Social presence enables learners to participate in the community, showing their individual personality, contributing their strength, and working toward enhancing their personal weaknesses concerning the learning contents. The dimension teaching presence is a functionality mainly relevant to the instructor of the courses, relating, for example, to designing learning activities and assessments [35].

Analyzing the identified research papers revealed a variety of different content delivery forms. TELEs can be integrated directly, based on files uploaded in the environment, web-based, offline content, and mobile content allowing access to learning content in handy formats [36]. Of course, more than one delivery form can be integrated into TELEs and used in parallel.

Another identified functionality is perceived affordances. Affordances relate to design features that support learners with solving their task. Different researchers refer to four types of affordances: cognitive, physical, sensory, and functional[37]. Cognitive affordance is "associated with the semantics or meaning of user interface artefacts" [38, p.646] such that the learners understand the TELEs' design, structure, and function. Physical affordance is a design feature enabling learners to physically interact with the interface artefacts. To illustrate a specific design feature, we refer to providing adequate headings for integrated artefacts. Sensory affordance refers to, for example, seeing, hearing, or feeling something in the TELE. Functional affordance is a "design feature that helps users accomplish work" [38, p.648]. [39] highlights the relevance of the affordances' design features for the development of an effective and efficient TELE that implements technology to ensure the design features reaching higher order learning and understanding of the learning content.

Another functionality of TELEs is personalization. This functionality is important to ensure students' retention within the TELEs [32]. Personalization can be reached through the offer of various applications, different concepts in parallel, and "the ownership of devices personalized" for the respective students [40, p.335].

TELEs differ according to the service level they provide for the users: traditional, personalized, and training on the job services [36]. Traditional learning services are based on either synchronous or asynchronous communication and service design, for example, chats vs. forums, while personalized services allow for providing individual learning support. Training on the job focuses on the continuous (individual) development for specifications and qualifications relevant to the current or future job [36].

Social networking as a TELE's functionality has received special attention in education research in the last couple of years [41, 42]. Like buttons afford the possibility not only of publishing learning content related posts but also of sharing other users' content, and can thus be "translated as a modern and technically transmitted form of the affirmation of a model - in terms of Social Learning Theory as reinforcement" [42, p.1238]. In addition to these three dimensions, the possibility of commenting on other learners' posts is highlighted [41]. For this reason, commenting is added as another dimension of the functionality social networking.

We derived the functionality tools distinguishing different forms of tools in TELEs according to their application area [43]: tools that support online lectures and presentations, tools that enable collaboration in networks, and discipline-based tools necessary for teaching discipline founded on practical learning [43].

Four dimensions represent the functionality usage: course administration [44], learning activities, interaction with the instructor, and learning assessment [30]. Many learning management platforms, such as Moodle, are used as tools in transferring and providing information and learning content $[44,45]$. Learning activities in TELEs are carried out as different tasks published separately in the learning environment, which result in low adaptivity potential. Interaction with the instructors also takes place in different kinds of activities. 
Table 2. Framework for taxonomy evaluation [46]

\begin{tabular}{|c|c|c|c|c|c|c|c|}
\hline \multirow{3}{*}{ 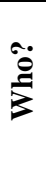 } & involvement & \multicolumn{3}{|c|}{ subject has been involved in taxonomy building } & \multicolumn{3}{|c|}{$\begin{array}{l}\text { subject has not been involved in taxonomy } \\
\text { building }\end{array}$} \\
\hline & background & \multicolumn{3}{|l|}{ academics } & \multicolumn{3}{|l|}{ practitioners } \\
\hline & experience & \multicolumn{3}{|l|}{ domain } & \multicolumn{3}{|l|}{ method } \\
\hline \multirow{3}{*}{ 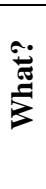 } & type & \multicolumn{3}{|c|}{ real-world } & \multicolumn{3}{|c|}{ about real-world } \\
\hline & involvement & \multicolumn{2}{|c|}{$\begin{array}{l}\text { object has been used in } \\
\text { taxonomy building }\end{array}$} & \multicolumn{2}{|c|}{$\begin{array}{l}\text { object has been used in taxonomy } \\
\text { building and evolved since then }\end{array}$} & \multicolumn{2}{|c|}{$\begin{array}{l}\text { object has not been used in } \\
\text { taxonomy building }\end{array}$} \\
\hline & coverage & \multicolumn{2}{|c|}{ exhaustive } & \multicolumn{2}{|l|}{ selective } & \multicolumn{2}{|c|}{ representative } \\
\hline \multirow{3}{*}{ 菅 } & approach & \multicolumn{3}{|c|}{ quantitative } & \multicolumn{3}{|l|}{ qualitative } \\
\hline & method & $\begin{array}{l}\text { logical } \\
\text { argument }\end{array}$ & $\begin{array}{l}\text { expert } \\
\text { interview }\end{array}$ & focus group & $\begin{array}{l}\text { illustrative } \\
\text { scenario }\end{array}$ & $\begin{array}{l}\text { Delphi } \\
\text { technique }\end{array}$ & $\begin{array}{l}\text { action } \\
\text { research }\end{array}$ \\
\hline & & $\log$ diary & case study & survey & sorting & experiment & $\ldots$ \\
\hline
\end{tabular}

Furthermore, the interaction with peers is an important functionality of learning technologies in the context of their use [30]. Integrating this dimension into TELEs varies from chat rooms to discussion boards and different collaboration tools [45]. Conducting and requesting assessments represent the third possible means of using learning technologies in TELEs [30, 45]. The above-mentioned four dimensions are referred to learning design activities [20], instead of referring to them by incorporating the term "usage". Other dimensions are assimilative, finding and handling information, communication, productive, experimental, interactive/adaptive, and assessment [20].

\section{Evaluating the functionality taxonomy}

To rigorously evaluate conducted actions and analyzed artefacts in information systems is highly relevant in ensuring that the proposed problem is actually solved in research [47]. Especially for developed taxonomies, the often lacking evaluation attracts criticism [46]. Szopinski et al. [46] understand the first two steps of the taxonomy development as an ex-ante evaluation, which ensures the objective ending conditions for the development but also highlight the lacking ex-post evaluation. Sorting is a validation possibility that focuses on the taxonomy' structure
[46]. We chose the sorting approach since it allows us to review how the different dimensions are assigned to the learning technologies. With the interrater reliability, we calculate experts' agreement regarding sorting the dimensions with the functionalities [46].

A framework for evaluating taxonomies is illustrated in Table 2 [46]. Four researchers who were not involved in the taxonomy development process and who are partly domain specific and partly familiar with taxonomy development sorted our taxonomy. The taxonomy of functionalities is a real-world object evaluation. The object has not been used in the taxonomy development and all dimensions of the taxonomy were sorted according to the functionalities; the coverage is therefore exhaustive. Furthermore, the evaluation of the taxonomy was conducted qualitatively based on sorting [46].

We provided the four sorting researchers with a short description of the functionalities without any reference to the relating dimensions. The researchers were asked to fill out the table with the dimensions belonging to the taxonomy of TELEs, using only the functionality column. All the taxonomy's dimensions were provided in alphabetical order to ensure an unrelated and independent list to be used for the sorting process. Furthermore, we asked the researchers to judge their own knowledge on developing taxonomies, and on TELEs.

Table 3. Taxonomy of ALS functionalities in technology-enhanced learning environments

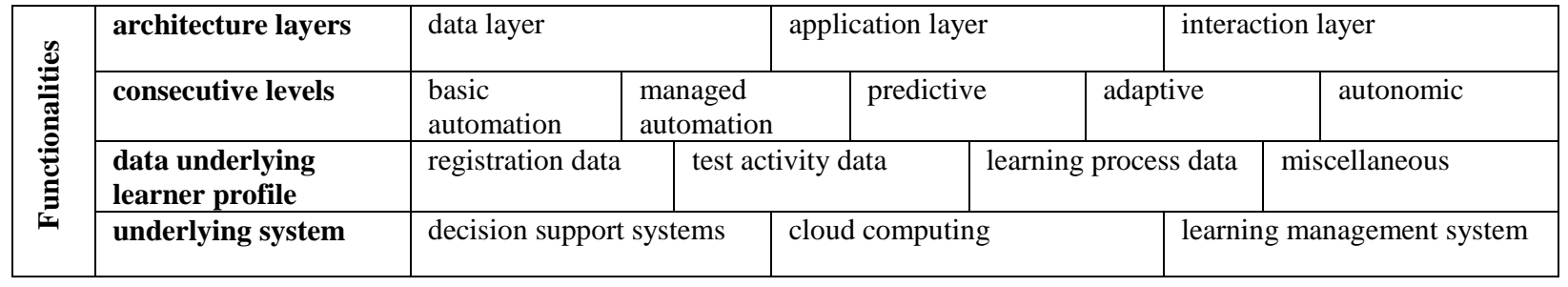


The researchers sorted $92.68 \%, 85.37 \%, 80.49 \%$ und $75.61 \%$ of the 41 dimensions (see Table1) to the correct functionality. During the evaluation, we established that basic knowledge of TELEs simplifies the dimension sorting, whereas the high number of dimensions and functionalities in our case makes sorting more difficult.

\section{Functionalities of ALSs}

With the first taxonomy, we introduce the different dimensions of functionalities in TELEs, which was an important step for further focusing on developing another taxonomy that specifies functionalities of ALSs. New functionalities in TELEs emerge, such as the possibility to integrate ALSs "accommodat[ing] the wide variety of personal, cultural and disciplinary diversity that defines quality teaching and learning" [48, p.15]. Again, following Nickerson et al.'s [1] steps, we pursued four iterations of the conceptual-to-empirical approach. The search for research papers to inform this second taxonomy is again based on EBSCOhost and LearnTechLib, and also on the AISel database. We added the latter database since the functionalities of ALSs are more specific, and only a few results could be obtained in the literature search (EBSCOhost returned zero papers with different search queries, LearnTechLib returned six papers, and AISel returned eight papers). In total, we identified four ALS functionalities illustrated in Table 3 above.

\subsection{Taxonomy of ALS functionalities}

The first functionality is architecture layers. The architecture of ALSs comprises three layers: the data, the application, and the interaction layer. The data layer stores information about the learners. This can be the properties of the learners but also the learning progress. The application layer includes all components that process the learning material. The interaction layer includes the learners' and instructors' graphical user interface and the visualization [15].

The functionality consecutive levels is adapted from the functionality adaptivity of TELEs, which has been explained above and follows [33]. The levels describe the development path and process from basic automation to full autonomy of the underlying TELEs for students. The autonomy to decide what, when, how and where to learn is only possible within certain predetermined areas. For example, the curriculum and thematic focus are predetermined and students can only influence these areas to a certain extent, even with "full autonomy".
"Learning analytics $[\ldots]$ is the central component of an adaptive learning system as it collects and analyzes user data on a real-time basis" [49, p.3], and thus the underlying learner profile is another relevant functionality. In the analyzed literature, we identified different sources of data: registration data, test activity data, and learning process data [50]. [51, p.125] name exemplified specifications that are relevant for ALSs, such as "personal context, knowledge, experience, interests, preferences, goals, needs, intentions, physical and psychological state, location, and other information." The dimensions of these functionalities are not complete, as they depend strongly on not only the underlying system used to implement ALSs in TELEs but also on the available data.

Another functionality identified in the literature is the underlying system. An ALS based on a decisionsupport system " recommends adaptive learning paths personalized to particular learners" [50, p.50]. Based on user data, the recommendations are presented to learners according to their previous success in assessments or other tasks. [52] focuses on adaptive learning on mobile devices, which is based on using cloud computing. Cloud storage makes content and access to learning options possible anytime and anywhere, which ensures around-the-clock availability [50]. Learning management systems offer another chance for integrating ALSs into TELEs.

\subsection{Research opportunities}

As the low number of scientific publications already indicated, research on functionalities, especially on ALSs, is capable of further development and improvement. We identified several opportunities that will profit from more research, also in the form of case studies or field studies conducted by academics as well as practitioners.

The first research opportunity (RO1) relates to the consecutive levels. Practitioners (e.g. lecturers, teachers, technical support and developer of TELEs and ALSs) particularly, would profit from a process model to better understand and enhance the change process toward full autonomy in learning opportunities. In addition, instructions for action could help shape the process in a targeted manner and best practices could also support the modification of specific underlying systems.

RO1: Researchers and practitioners should develop process models, for example, based on the consecutive levels supporting the effective integration of ALSs into TELEs.

As already indicated above, different underlying data sets with information on learners are important for ALS use relating to the second research 
opportunity: Country-specific studies are especially conceivable, since the data (mining) that are available and legally usable for learning analytics depend on the country-specific requirements.

RO2: Researchers and practitioners should analyze and discuss country-specific circumstances concerning the data underlying ALS and resulting effects on ALS usage and implementation.

RO3 refers to the underlying system. With the decreasing costs of technology, the spread of technologies increases and allows for their integration into the learning context. Mobile learning opportunities for adaptive learning may lead to cost reduction, mobile technologies' increased accessibility in the learning context, and such technologies becoming increasingly integrated into the learning environment increase the potential of innovation, such as augmented reality, for ALSs [52].

RO3: Researchers and practitioners should not only test and evaluate new technological developments in ALS but also exchange studies and best practices with other scientists and teachers.

Of course, the taxonomy itself also requires further research and provides opportunities for adding more functionalities that could be identified while interviewing ALS experts or using the dolphin method that allows the experts to actively contribute to the enhancements. Developing design features of functionalities could support ALS implementation in TELEs to enable the offers of personalization in accordance with students' characteristics.

RO4: Researchers and practitioners should discuss and develop the functionalities and dimensions to enhance knowledge about ALS functionalities.

\section{Discussion and outlook}

Developing a taxonomy of functionalities in TELEs as a first step, we proposed a fundamental taxonomy. After a structured evaluation using sorting, we introduced a second taxonomy specifically for ALSs as part of TELEs, which supports the structural design for the ALS functionalities. Nickerson et al.'s [1] method is widely accepted for taxonomy development in information systems [e.g. 46]. The addition of further dimensions to our taxonomy is possible if "new types of object appear" [1, p.341], which, for a start, could be explored in the second taxonomy development. While the first taxonomy was developed very broadly for TELEs, functionalities of ALSs in TELEs are rather specific and, therefore, the fundamental taxonomy is adaptable and extendable to other contexts and applications.

The paper deals with the research challenge of identifying functionalities of TELEs and associated
ALSs, which enhance the learning experience on an individual level. We extended the knowledge about TELEs, ALSs, and their functionalities as it is of increasing importance to universities, researchers, and practitioners. With our research, we contribute to the research of giving a descriptive and structured investigation of the functionalities.

We contribute to the body of knowledge by supporting researchers and practitioners identify the different functionalities and their dimensions. Such support has an impact on their design decisions and stimulate testing different functionalities in TELEs for their specific learning content. In addition, we support learning and teaching in TELEs with our structured analysis and taxonomy development, particularly in this turbulent and challenging time of the coronavirus crisis. Many courses have to be held in TELEs and have to be implemented within a very short time frame. In the future, our structuring can support this.

Furthermore, with the two taxonomies, we contribute to the investigation of existing TELEs and ALSs by identifying and developing new approaches, designs and application of these concepts not only in higher education but also in other learning settings. Practitioners may use the taxonomies to compare their own design initiatives with other concepts, while the taxonomies can be used as a conceptual basis and first step for theorizing. In the future we indent to develop a design theory for the integration of ALSs in TELEs.

There are thus opportunities for fellow researchers to examine application possibilities of TELEs and especially ALSs, as well as their functionalities for specific learning content in (already) implemented and running learning (management) systems. Another means of addressing this research topic scientifically is to conduct a survey, targeting students who study at a distance learning university, on a variety of integrated functionalities in their TELEs. For the medium-term future, it could then be possible to integrate recommendation systems into TELE, which propose individual learning opportunities that optimize university learning with the help of various functionalities. Other aspects, which require further investigation to enable the effective use of these possibilities in TELEs, are the currently valid legal conditions and examination regulations. These conditions and regulations might require further development to offer such digital learning opportunities in a legally secure manner [53].

Finally, our paper has a number of shortcomings that could be addressed in further research. The first concerns our research design. Having limited ourselves to certain selected databases excludes possible additional research from being identified as relevant for the taxonomies. The second concerns the 
use of a different evaluation method, which will allow discussions with TELE researchers. The use of a different evaluation method could possibly also lead to a higher quality feedback and further modifications or clarifications between dimensions, which could be achieved, for example, by a Delphi approach.

\section{References}

[1] Nickerson, R.C., U. Varshney, and J. Muntermann, "A method for taxonomy development and its application in information systems", European Journal of Information Systems, 22, 2013, pp. 336-359.

[2] Haslam, C.R., S. Madsen, and J.A. Nielsen, "Crisisdriven digital transformation: Examining the online university triggered by COVID-19", ISPIM Innovation Conference, 2020.

[3] Mohmmed, A.O., B.A. Khidhir, A. Nazeer, and V.J. Vijayan, "Emergency remote teaching during Coronavirus pandemic: the current trend and future directive at Middle East College Oman", Innovative Infrastructure Solutions, 5(3), 2020.

[4] Vladova, G., A. Ullrich, B. Bender, and N. Gronau, "Students' Acceptance of Technology-Mediated Teaching - How It Was Influenced During the COVID19 Pandemic in 2020: A Study From Germany", Frontiers in psychology, 12, 2021, p. 636086.

[5] Mora Cortez, R. and W.J. Johnston, "The Coronavirus crisis in B2B settings: Crisis uniqueness and managerial implications based on social exchange theory", Industrial Marketing Management, 88, 2020, pp. $125-135$.

[6] Cerinšek, G., S.A. Petersen, and T. Heikura, "Contextually enriched competence model in the field of sustainable manufacturing for simulation style technology enhanced learning environments", Journal of Intelligent Manufacturing, 24(3), 2013, pp. 441-455.

[7] Kok, A., "Understanding the Technology Enhanced Learning Environments from A Cognitive Perspective", International Education Studies (IES), 2(4), 2009.

[8] Ennouamani, S. and Z. Mahani, "An overview of adaptive e-learning systems", pp. 342-347.

[9] Zhang, S. and H.H. Chang, "From smart testing to smart learning: how testing technology can assist the new generation of education", International Journal of Smart Technology and Learning, 1(1), 2016, p. 67.

[10] Atkinson, R.C., Adaptive Instructional Systems: Some Attempts to Optimize the Learning Process, Stanford University, Institute for Mathematical Studies in the Social Sciences, 1974.

[11] Bergdahl, N., J. Nouri, and U. Fors, "Disengagement, engagement and digital skills in technology-enhanced learning", Education and Information Technologies, 25(2), 2020, pp. 957-983.

[12] Lwoga, E., "Critical success factors for adoption of web-based learning management systems in Tanzania", International Journal of Education and Development using ICT, 10(1), 2014.
[13] Adorni, G., M. Coccoli, and I. Torre, "Semantic Web and Internet of Things Supporting Enhanced Learning", Journal of e-Learning and Knowledge Society, 8(2), 2012, pp. 23-32.

[14] Battou, A., "Designing an Adaptive Learning System Based on a Balanced Combination of Agile Learner Design and Learner Centered Approach", American Scientific Research Journal for Engineering, Technology, and Sciences, 37(1), 2017, pp. 178-186.

[15] Cecilia, M.R., P. Vittorini, and F. Di Orio, "An Adaptive Learning System for Developing and Improving Reading Comprehension Skills", Journal of Education Research, 10(4), 2016, pp. 195-236.

[16] van Bergen, H., S. Edwards, and N. van der Stap, Blended learning: the student owns his learning environment, Austin, Texas, USA, March 5-9, 2017.

[17] Kamat, P., S. Patil, and K. Kadam, "Design Patterns for Effective Technology Enabled Learning", International Journal of Advanced Engineering Research and Science (IJAERS), 4(1), 2016, pp. 168-171.

[18] Holmes, W., S. Anastopoulou, H. Schaumburg, and M. Mavrikis, "Technology-enhanced personalised learning: Untangling the evidence", 2018.

[19] Mangaroska, K. and M. Giannakos, "Learning Analytics for Learning Design: A Systematic Literature Review of Analytics-Driven Design to Enhance Learning", IEEE Transactions on Learning Technologies, 12(4), 2019, pp. 516-534.

[20] Rienties, B., Q. Nguyen, W. Holmes, and K. Reedy, "A review of ten years of implementation and research in aligning learning design with learning analytics at the Open University UK", Interaktion Design and Architecture(s)(33), 2017, pp. 134-154.

[21] Farrow, R., "Mobile learning: a meta-ethical taxonomy", 2011.

[22] Kim, M.S., "Developing a competency taxonomy for teacher design knowledge in technology-enhanced learning environments: a literature review", Research and Practice in Technology Enhanced Learning, 14(1), 2019, p. 47.

[23] White, G., "Adaptive Learning Technology Relationship with Student Learning Outcomes", Journal of Information Technology Education, 19, 2020, pp. 113-130.

[24] Biten, S.Y., "Adaptive Learning Technologies to Personalize Learning Environment", in Proceedings of Society for Information Technology \& Teacher Education International Conference, P. Resta and S. Smith, Editors. 2017. Association for the Advancement of Computing in Education (AACE): Austin, Texas, USA.

[25] Wagner, J., "Computer-Based Adaptive Learning in Higher Education", in Proceedings of Society for Information Technology \& Teacher Education International Conference, P. Resta and S. Smith, Editors. 2017. Association for the Advancement of Computing in Education (AACE): Austin, Texas, USA.

[26] Serhan, D., "Students' Attitudes toward the Use of Adaptive Learning Systems in Learning College Algebra", in Proceedings of Society for Information Technology \& Teacher Education International 
Conference, P. Resta and S. Smith, Editors. 2017. Association for the Advancement of Computing in Education (AACE): Austin, Texas, USA.

[27] Homer, B. and J. Plass, "Innovating Randomized Effectiveness Trials: The Case of an Adaptive Learning Engine for E-Learning in High Schools", in E-Learn: World Conference on E-Learning in Corporate, Government, Healthcare, and Higher Education, Association for the Advancement of Computing in Education (AACE), Editor, Kona, Hawaii. 2015.

[28] Lösser, B., A.M. Oberländer, and D. Rau, Taxonomy Research in Information Systems: A Systematic Assessment, 2019.

[29] Sun, Q., T.J. Norman, and Y. Abdourazakou, "Perceived value of interactive digital textbook and adaptive learning: Implications on student learning effectiveness", Journal of Education for Business, 93(7), 2018, pp. 323-331.

[30] Raspopovic, M., S. Cvetanovic, and A. Jankulovic, "Challenges of transitioning to e-learning system with learning objects capabilities", International Review of Research in Open and Distributed Learning, 17(1), 2016, pp. 123-147.

[31] Poore-Pariseau, C., "Accessabilty and Instuctional Design in E-Learning", International Handbook of ELearning Volume 1: Theoretical Perspectives and Research, 2015, pp. 257-267.

[32] Hyman, J.A., "Developing Instructional Materials and Assessments for Mobile Learning", International Handbook of E-Learning Volume 1: Theoretical Perspectives and Research, 2015, pp. 319-330.

[33] Woodside, J.M., W. Sause, and S. Amiri, "Autonomic Assessments: An E-Learning Model", in EdMedia + Innovate Learning 2016, Association for the Advancement of Computing in Education (AACE), Editor. 2016: Vancouver, BC, Canada.

[34] Mnkandla, E. and A. Minnaar, "The Use of Social Media in E-Learning: A Metasynthesis", The International Review of Research in Open and Distributed Learning, 18(5), 2017.

[35] Garrison, D.R., T. Anderson, and W. Archer, "Critical inquiry in a text-based environment: Computer conferencing in higher education", The internet and higher education, 2(2-3), 1999, pp. 87-105.

[36] Bouquet, P. and A. Molinari, "Semantic Technologies and e-Learning: towards an entity-centric approach for Learning Management Systems", Journal of e-Learning and Knowledge Society, 8(2), 2012, pp. 65-84.

[37] Hartson, R., "Cognitive, physical, sensory, and functional affordances in interaction design", Behaviour \& Information Technology, 22(5), 2003, pp. 315-338.

[38] Hartson, R. and P.S. Pyla, The UX Book: Process and guidelines for ensuring a quality user experience, Elsevier, 2012.

[39] Pellerin, M., "Language Tasks Using Touch Screen and Mobile Technologies: Reconceptualizing Task-Based CALL for Young Language Learners", Canadian Journal of Learning and Technology / La revue canadienne de l'apprentissage et de la technologie, 40(1), 2014.
[40] Crompton, H., "A Theory of Mobile Learning", International Handbook of E-Learning Volume 1: Theoretical Perspectives and Research, 2015, pp. 309317.

[41] Adham, R., P. Parslow, Y. Dimitriadi, and K. Lundqvist, "The Use of Avatars in Gender Segregated Online Learning Within MOOCs in Saudi Arabia - A Rwaq Case Study", The International Review of Research in Open and Distributed Learning, 19(1), 2018.

[42] Panke, S., C. Kohls, and B. Gaiser, "Social Media and Seamless Learning: Lessons Learned", Journal of Educational Multimedia and Hypermedia, 26(3), 2017, pp. 285-302.

[43] Amemado, D., "Integrating Technologies in Higher Education: Common Reasons for Integrating and Required Educational Features", World Conference on Educational Media \& Technology, 2012.

[44] Cabero-Almenara, J., M. Arancibia, and A. del Prete, "Technical and Didactic Knowledge of the Moodle LMS in Higher Education. Beyond Functional Use", Journal of New Approaches in Educational Research (NAER Journal), 8(1), 2019, pp. 25-33.

[45] Kok, A., "How to Manage the Inclusion of E-Learning in Learning Strategy: Insights from a Turkish Banking Institution", International Journal of Advanced Corporate Learning (iJAC), 6(1), 2013, pp. 20-27.

[46] Szopinski, D., T. Schoormann,, and D. Kundisch,, "Because your taxonomy is worth it: Towards a framework for taxonomy evaluation", Proceedings of the European Conference on Information Systems (ECIS), 2019.

[47] Peffers, K., T. Tuunanen, M.A. Rothenberger, and S. Chatterjee, "A design science research methodology for information systems research", Journal of Management Information Systems, 24(3), 2007, pp. 45-77.

[48] Anderson, T. and J. Dron, "Integrating learning management and social networking systems", Italian Journal of Educational Technology, 25(3), 2017, pp. 519.

[49] Nguyen, A., L. Gardner, and D. Sheridan, "A MultiLayered Taxonomy of Learning Analytics Applications", PACIS Proceedings, 2017.

[50] Yarandi, M., H. Jahankhani, and A.-R. Tawil, "Towards Adaptive E-Learning using Decision Support Systems", International Journal of Emerging Technologies in Learning (iJET), 8(2013), 2013.

[51] Medina-Medina, N. and L. García-Cabrera, "A taxonomy for user models in adaptive systems: special considerations for learning environments", The Knowledge Engineering Review, 31(2), 2016, pp. 124141.

[52] Squires, D.R., "M-Learning: Implications in Learning Domain Specificities, Adaptive Learning, Feedback, Augmented Reality, and the Future of Online Learning", Journal of Educational Technology, 11(3), 2014, pp. 1-8.

[53] European Commission, "Digital Education at School in Europe: Eurydice Report", 2019. 